\title{
NEGOCIOS POR CORRESPONDENCIA ENTRE CÁDIZ Y TENERIFE, 1790-1799
}

\section{GUADALUPE CARRASCO GONZÁLEZ | UNIVERSIDAD DE CÁDIZ}

\author{
ORCID iD: 0000-0002-5843-5811
}

\begin{abstract}
RESUMEN
En este artículo se exploran algunos de los negocios propiciados por la relación de correspondencia existente entre Eduardo $\gamma$ Jacobo Gough y compañía, de Cádiz y la Casa de comercio Cólogan de Tenerife, en la última década del siglo XVIII: contratación de pólizas de seguro, comercio de harina y trigo, de frutos de Indias como añil, azúcar y cacao, y de otras provisiones como la carne salada. Para ello, se ha utilizado la correspondencia remitida desde Cádiz por la casa Gough, conservada en el Fondo Zárate-Cólogan del Archivo Histórico Provincial de Santa Cruz de Tenerife.
\end{abstract}

PALABRAS CLAVE

Cádiz, Gough, Cólogan, Seguros marítimos, Harina, Azúcar.

This article explores some of the businesses fostered by the correspondence relationship between Eduardo and Jacobo Gough \& Co. from Cádiz and the trade house of Cólogan from Tenerife, in the last decade of the 18th century: hiring of insurance policies, trade in flour and wheat, products of Indies such as indigo, sugar and cocoa, and other provisions such as salty meat. For this, the correspondence sent from Cádiz by the Gough house has been used, which is kept in the Zárate-Cólogan Collection of Archivo Histórico Provincial de Santa Cruz de Tenerife.

\section{KEYWORDS}

Cádiz, Gough, Cólogan, Maritime insurance, Flour, Sugar. 


\section{INTRODUCCIÓN}

finales del siglo XVIII la distancia entre Cádiz y Canarias oscilaba entre los siete
días de navegación del viaje de ida y los veinticinco días de navegación del viaje
de vuelta, y probablemente esta distancia no había cambiado demasiado en los
dos siglos inmediatamente anteriores. El sistema de vientos portantes mantenía al archipiélago conectado con los puertos de la costa atlántica de Andalucía. Esta circunstancia geográfica contribuyó a convertir a la bahía de Cádiz en un nudo fundamental de las conexiones con Canarias. De allí partieron las expediciones de conquista y, tras esta, los puertos gaditanos establecieron un intenso tráfico comercial que abastecía a las islas de todo tipo de mercancías a cambio de productos como azúcar y tintes ${ }^{1}$. Cádiz también fue la escala obligada y de trasbordo del comercio mediterráneo con Canarias. En 1503 la fundación en Sevilla de la Casa de Contratación, además, convirtió a las islas, no solo en una escala logística para las flotas de Indias, sino en una pieza clave del sistema de navegación y comercial que fue la Carrera de Indias. El traslado a Cádiz de la Casa de Contratación y del Consulado de Cargadores, acercó todavía más Cádiz y Canarias. De Cádiz partían con destino a América las flotas y registros, que en su periplo recalaban necesariamente en Canarias. Pero, aunque la ruta de regreso marginaba a Canarias, el flujo de mercancías hacia las islas se mantenía. Todo este tráfico estructural se completaba con las conexiones que los puertos canarios establecieron, desde muy pronto, con otros europeos y americanos ajenos al monopolio español.

Naturalmente, estas rutas involucraron mercancías, instrumentos financieros, comerciantes, correspondientes y agentes, que como piezas de un engranaje movían la maquinaria que permitía la comunicación eficaz entre Cádiz y Canarias. En definitiva, Cádiz era el centro redistribuidor de caudales y mercancías extranjeras, nacionales y coloniales, servía de puente en los circuitos de letras de cambio y en centro de contratación de seguros marítimos ${ }^{2}$.

1 Existe una abundante bibliografía sobre las relaciones comerciales entre Cádiz y Canarias en los siglos XV y XVI. AZNAR VALLEJO, Eduardo y GONZÁLEZ ZALACAÍN, Roberto J. (coords.): De mar a mar. Los puertos castellanos en la Baja Edad Media, La Laguna, 2015. AZNAR VALLEJO, Eduardo. Las relaciones comerciales entre Andalucía y Canarias a finales del siglo XV y comienzos del siglo XVI, en Hacienda y comercio. Actas del II Coloquio de Historia Medieval Andaluza, Sevilla, 8-10 de Abril, 1981, Sevilla, Diputación, 1982 Pp. 269-282. LOBO CABRERA, Manuel. El comercio canario europeo bajo Felipe II, Santa Cruz de Tenerife, Ediciones Idea, 2008. LOBO CABRERA, Manuel. Sevilla, Gran Canaria y las Indias en el siglo XVI en ACOSTA GUERRERO, Elena (coord.): XX Coloquio de Historia Canario-Americana, Las Palmas, Cabildo Insular de Gran Canaria, 2014, págs. 231-245.

2 GUIMERÁ RAVINA, Agustín. Burguesía extranjera y comercio atlántico. La empresa comercial irlandesa en Canarias (17031771), Santa Cruz de Tenerife, CSIC, 1985, p. 255. SOLBES FERRI, Sergio. La navegación directa de Canarias a América y su papel en el sistema comercial atlántico, 1718-1778. América Latina en la Historia Económica, vol. 25 [en línea], 1 ene. /abr., 2018. http://www.scielo.org.mx/scielo.php?script=sci_arttext\&pid=S1405-22532018000100036 
Para aproximarme a este entramado comercial voy a utilizar una parte de la correspondencia epistolar remitida por la casa mercantil, establecida en Cádiz, titulada Eduardo $\gamma$ Jacobo Gough, compañía a los comerciantes canarios Juan y Tomás Cólogan de Tenerife. La correspondencia, con ser una fuente poco habitual, es en este caso, excepcional para este artículo porque por ella transitan negociaciones comerciales, financieras y asuntos legales, integrados en las relaciones sociales y familiares y en los intereses ajenos y personales de los socios de ambas compañías. Sin embargo, la gran cantidad de misivas que intercambiaron ambas casas comerciales me obliga a seleccionar un periodo concreto. Pero, ni siquiera con esta restricción es posible analizar con exhaustividad su contenido, por lo que se considerará únicamente el tratamiento que en dicha correspondencia se hace de algunos de los negocios que interesaron a los comerciantes canarios, y la manera cómo se gestionaba la información comercial entre ambas casas comerciales para despachar finalmente las dependencias. Este análisis conlleva inevitablemente abordar la dinámica de las comunicaciones entre Cádiz y las Islas.

La correspondencia mercantil ha tenido desde la década de los años cincuenta del pasado siglo una gran tradición historiográfica. Y en los últimos años, la utilización de herramientas metodológicas como la teoría de redes en disciplinas como la economía, la sociología y la historia, ha permitido revalorizar la correspondencia como fuente histórica ideal para la aplicación de sus presupuestos metodológicos, particularmente en cuestiones como los comportamientos sociales de los comerciantes a escala individual, familiar y cultural; el modo de gestionar los negocios, la percepción individual y colectiva de la situación económica, el desarrollo de los negocios, las prácticas y usos comerciales o el análisis de la circulación de las mercancías. Los epistolarios se convierten así en una fuente interdisciplinar que interesa no solo a los historiadores, sino a los filólogos ${ }^{3}$, antropólogos y sociólogos. En el ámbito de la historia, la correspondencia ha sido una fuente habitual en los estudios sobre América ${ }^{4}$ y sobre el comercio. Y es precisamente la historiografía sobre el comercio la que ha tropezado con mayores dificultades a la hora de encontrar epistolarios de comer-

3 PADRÓN FERNÁNDEZ, Rafael (ed.). Ensayos sobre epistolografía en el siglo de las Luces, Santa Cruz de Tenerife, Editorial Idea, 2013, Pp.81-132. BANNET, Eve T.: Empire of Letters. Letter Manuals and Trasatlantic Correspondence, 1688-1820, Cambridge, University Press, 2005

4 OTTE, Enrique. Cartas privadas de emigrantes a Indias, 1540-1616, Sevilla, 1988. MACÍAS DOMÍNGUEZ, Isabelo y MORALES PADRÓN, Francisco. Cartas desde América, 1700-1800, Sevilla, 1991; USUNÁRIZ, José María. Una visión de la América del siglo XVIII. Correspondencia de emigrantes guipuzcoanos y navarros, Madrid, Mapfre, 1992; MÁRQUEZ MACÍAS, Rosario. Historias de América: la emigración española en tinta y papel, Huelva 1994; SÁNCHEZ RUBIO, Rocío y TESTÓN NÚÑEZ, Isabel. El hilo que une. Las relaciones epistolares entre el Viejo $\gamma$ Nuevo Mundo (siglos XVI-XVIII), Mérida, Universidad de Extremadura, 1999; MARTÍNEZ MARTÍNEZ, M. Carmen. Desde la otra orilla. Cartasde Indias en el Archivo de la Real Chancillería de Valladolid (siglos XVI-XVIII), León: Universidad, 2007. 
ciantes $^{5}$. No cabe duda de que la correspondencia de la casa Cólogan merecería un análisis más exhaustivo que el que aquí se presenta. Considérese, pues, éste como un anticipo de las posibilidades que ofrece esta fuente.

\section{DE CÁDIZ A CANARIAS: LA CORRESPONDENCIA REMITIDA POR LA CASA DE COMERCIO DE EDUARDO Y JACOBO GOUGH DE CÁDIZ, A JUAN Y TOMÁS CÓLOGAN, EN TENERIFE}

Entre los extensos fondos documentales de la familia Valois-Cólogan que se conservan en el fondo Zarate-Cólogan del Archivo Histórico Provincial de Santa Cruz de Tenerife ${ }^{6}$ destaca la abundante correspondencia que, tanto Bernardo Valois como Juan y Tomás Cólogan, mantuvieron con multitud de correspondientes distribuidos por Europa y América $^{7}$. Y es de entre esta correspondencia, de donde hemos entresacado las cartas remitidas por la compañía gaditana Eduardo y Jacobo Gough.

El apellido Gough aparece en Cádiz ligado a actividades comerciales en la segunda década del siglo XVIII, cuando Diego Gough y Brown se establece en Cádiz después de haber servido en la marina española en los años 1718 y $1722^{8}$. En 1727 se uniría en matrimonio con Francisca Valois, hija del comerciante irlandés Bernardo Valois y de Francisca Fitztgerald. De este matrimonio nacieron Eduardo Martin (1729) y Jacobo Ignacio Ricardo Gough (1732), que primero de forma independiente y luego constituyendo la compañía de Eduardo y Jacobo Gough participaron activamente en la Carrera de Indias.

La ascendencia irlandesa orientó y reforzó buena parte de sus relaciones familiares y comerciales ${ }^{9}$, siendo así que la compañía Gough llegó a convertirse, no solo en una de

5 Sirva como muestra los dos trabajos más recientes de edición y análisis de correspondencia comercial: MARTíNEZ RUIZ, José Ignacio y GAUCI, Perry. Mercaderes ingleses en Alicante en el siglo XVII. Estudio y edición de la correspondencia comercial de Richard Houncell \&Co, Alicante, Publicaciones de la Universidad de Alicante, 2008, MONTOJO MONTOJO, Vicente. Correspondencia mercantil en el siglo XVII: Las cartas del mercader Felipe Moscoso (1660-1685), Murcia, Universidad de Murcia, 2013.

6 Archivo Histórico Provincial de Santa Cruz de Tenerife (AHPT), Fondo Zárate-Cólogan (FZC).

7 Se han publicado algunas de estas cartas en ARBELO GARCIA, Adolfo. Al recibo de esta... Relaciones epistolares canarioamericanas del siglo XVIII, Santa Cruz de Tenerife, Ediciones Idea, 2010.

8 Por Real Decreto de 10 de marzo de 1750 se concede a Diego Gough Carta y privilegio de hidalguía. Revista Hidalguía, XXVII, 157, nov-dic, 1979.

9 Ambos hermanos contrajeron matrimonio con mujeres también de origen irlandés: Luisa Crew (1753) y Teresa Quilty (1760). Del matrimonio de Eduardo Gough y Luisa Crew nació Ricardo Gough que en 1783, cuando muere su padre tenía 13 años. Del matrimonio de Jacobo Gough y María Teresa Quilty nacieron cuatro hijos, dos que murieron párvulos, Eduardo y Elena (casada con D. Antonio Viñafañe, caballero pensionado de la Orden de Carlos III, falleció en Madrid en 1793). Archivo Histórico Provincial de Cádiz (AHPC), Protocolos Notariales (PN), Cádiz, 1705, f. 493-496. 
las compañías de comercio importantes de Cádiz, sino en una pieza clave en la estructura comercial de la casa Cólogan y, por tanto, en el principal apoyo y conexión de la empresa canaria en Cádiz y con el comercio de Indias.

Sobre los negocios de la compañía Gough no tenemos muchos datos a excepción de su actividad como correspondientes de los Valois-Cólogan. Sabemos que en 1759 Jacobo, residía en la casa de su padre y que se "aplicaba en el comercio y la navegación a las Indias...por si solo para el adelantamiento de su fortuna" y que entonces estaba preparando un nuevo viaje a las Indias ${ }^{10}$. En ese mismo año Eduardo Gough estaba asociado con su padre Diego ${ }^{11}$ y, unos años después, sin que podamos determinar la fecha, los hermanos, Eduardo y Jacobo Gough establecieron una compañía muy activa en el comercio de todo tipo de mercancías con América ${ }^{12}$. Según J.G. Pacheco Traconis, los Gough eran uno de los principales importadores de añil. Entre 1775 y 1778 les fueron consignados el 17\% de todo el añil que llegó a Cádiz ${ }^{13}$.

En junio de $1783^{14}$ falleció Eduardo, pero la compañía continuó su actividad conservando la misma razón social: Eduardo y Jacobo Gough, compañía, al menos hasta 1795, año en el que Ricardo Gough Crew, hijo de Eduardo Gough, se separó de la sociedad ${ }^{15}$. A partir de entonces, la correspondencia epistolar desde Cádiz será remitida por las dos casas de negocios resultantes: la de Ricardo Gough, que se estableció por su cuenta con el dinero que le tocó de la liquidación de los bienes de la compañía correspondientes a su padre ${ }^{16}$, y la de Jacobo Gough, con Pedro Domecq como apoderado y administrador.

10 AHPC, PN Cádiz, 1851, 9/07/1759. Había viajado a Veracruz en 1754. Archivo General de Indias (AGI), Contratación, 5496, N.3 R.48

11 AHPC, PN, Cádiz, 1851, 9/06/1759. Compromiso entre Juan Santiago Lobo Y Diego y Eduardo Gough.

12 Entre 1765 y 1767 cargaron libros con destino a Veracruz y La Guaira. Véase GÓMEZ ÁLVAREZ, Cristina. Navegar con libros. El comercio de libros entre España Y Nueva España (1750-1820), Madrid, Trama Ed., 2011, anexos 1 y 2. PANERA RICO, Carmen M. "La compañía Guipuzcoana de Caracas y el comercio de libros: un compromiso con la modernidad", Itsas Memoria, revista de Estudios marítimos del Pais Vasco, 2, 1998. P. 542. También importaron grandes cantidades de añil entre 1775 y 1778.

13 PACHECO TRACONIS, José Germán. El Añil: Historia de un cultivo olvidado en Venezuela, 1767-1870, Tesis doctoral, Universidad Autónoma de Barcelona, Barcelona, 2000, t.II, p. 459.

14 Testamento de Eduardo Gough hecho por su esposa Luisa Crew, 1 de octubre de 1784. AHPC, PN Cádiz, 1672.

15 Carta de Eduardo y Jacobo Gough, compañía a Juan Cólogan, fechada en Cádiz el 1 de octubre de 1795, donde dice: “Tenemos el honor de prevenir a vms que con motivo de haber cumplido su menor edad el señor Ricardo Gough, hijo de nuestro difunto hermano y socio don Eduardo, y habernos manifestado sus deseos de girar por sí solo, queda disuelta la compañía". AHPT, FZC, 1086/60.

16 En ese mismo año de 1795 Ricardo Gough se asocia con Jaime Picaluga quien se interesó por una quinta parte de los negocios de la compañía, "pero sin participación en los gastos, ni responsabilidad en los quebrantos" que ocurran. AHPC, PN Cádiz, 408, 24/12/1795. 
Algunos testimonios de comerciantes recogidos en la correspondencia de los Cólogan, pueden arrojar algo de luz sobre las actividades comerciales de la casa Gough. En la carta que Mateo Ferrara escribió a Juan Cólogan el 17 de febrero de 1799 explicaba que había propuesto a Pedro Domecq, que la casa Gough invirtiera y participara con algún interés en la expedición desde y hacia algunos puertos africanos, pero "nuestro don Pedro no se acomoda con otra cosa sino con sus descuentos de letras" ${ }^{17}$. Efectivamente, cuando se repasan los protocolos notariales gaditanos en busca de documentos justificativos de las actividades de la casa Gough, los protestos de letras de cambio constituyen el grueso de la documentación.

La correspondencia remitida por la propia casa Gough también ofrece algunas claves sobre sus negocios, ya que, si bien los asuntos tratados en las misivas se refieren a intereses de la casa Cólogan, algunas referencias nos hacen sospechar que en esos negocios los Gough no actuaban solo como agentes, sino que compartían riesgos en algunas operaciones. En 1796 Pedro Domecq declaraba que en una partida de seda que la casa Cólogan había enviado a Cádiz para su venta, "han establecido una cuenta a mitad entre ambas casas" (Gough y Cólogan $)^{18}$. Tal vez por eso Ricardo Gough advierte a Juan Cólogan que su relación "pueda dar fomento a nuestra correspondencia con recíproca utilidad" ${ }^{19}$.

Si consideramos el número de cartas remitidas a la empresa Valois-Cólogan desde Cádiz por las distintas casas de negocios de la familia Gough a lo largo del siglo XVIII, Cádiz ocupaba el segundo lugar después de Londres en el entramado comercial y financiero de la empresa canaria. Por supuesto, Londres era sede de la compañía hermana Cólogan, Pollard E Cooper y constituía el mercado principal para sus vinos, al tiempo que era también centro de pagos y asegurador, mientras que Cádiz era la conexión con los negocios en América (La Habana, Caracas y La Guaira), el Mediterráneo y también centro de pagos y sede aseguradora a la par que Londres.

Se han conservado 2303 cartas remitidas por diferentes comerciantes desde Cádiz a la casa Valois-Cólogan a lo largo del siglo XVIII, de las cuales este artículo se centrará en las 719 que corresponden al periodo 1790-1799. En este periodo un 60\% de esas cartas fueron enviadas por la compañía de Eduardo y Jacobo Gough, por alguno de sus socios o por su escribiente,

\footnotetext{
17 AHPT, FZC, 1181/45, Cádiz 17 de febrero de 1799, de Mateo Ferrara a Juan Cólogan.

18 AHPT, FZC, 1111/55, Cádiz 8 de enero de 1796

19 AHPT, FZC, 1125/08, Cádiz 1 de diciembre de 1795, de Ricardo Gough a Juan Cólogan
} 
Pedro Domecq, en nombre de la compañía. El resto de las cartas se repartieron entre un numeroso grupo de comerciantes de Cádiz que mantuvieron negocios de manera esporádica con la empresa canaria ${ }^{20}$.

El apretado registro de cartas expedidas desde Cádiz a lo largo del siglo muestra no solo la estrecha relación familiar y comercial existente entre las dos casas de negocios, sino la disponibilidad de medios para el envío de la correspondencia. Efectivamente, las cartas se enviaban por los correos regularmente establecidos directamente a Canarias o indirectamente a través de Lisboa, Londres, Hamburgo ${ }^{21}$ o La Coruña. Pero también se aprovechaba el tráfico constante de embarcaciones que salían hacia el archipiélago. Sorprende la regularidad y la prontitud en las contestaciones ya que, por ejemplo, en el año 1791 el tiempo de respuesta entre la llegada de una carta de Canarias y la respuesta del escribiente de la casa Gough, Pedro Domecq, era de unos 7 días ${ }^{22}$. Esta puntualidad se podía romper por dos razones: en primer lugar porque los encargos o los negocios sobre los que la Casa Cólogan informaba o solicitaba cierto servicio, necesitaran de más tiempo para ser resueltos, entonces ante la falta de noticias desde Cádiz, las cartas que llegaban desde Canarias, solicitando información, se acumulaban en el escritorio de los Gough (algunas eran duplicados enviadas por distintas vías). Así, en la larga misiva escrita el 26 de abril de 1792, Pedro Domecq, en nombre de los señores Gough, responde al requerimiento que en sucesivas cartas (23, 25 y 27 de febrero y 31 de marzo) le hicieron desde Canarias sobre asuntos de cierta urgencia, como la remisión de varias letras para su aceptación, asuntos relativos a bienes de difuntos, pagos y cobros pendientes, la llegada a salvamento de remesas de seda y carne salada, etc.

El tráfico constante entre Cádiz y las islas ayudaba, sin duda, a esta regularidad en la correspondencia. El movimiento de navíos entre Cádiz y Canarias obtenido del registro de embarcaciones del Diario de la Vigía ${ }^{23}$ en la década final del siglo XVIII, aunque incompleto, puede servirnos para entender la dinámica y la frecuencia de ese flujo de información.

20 Entre ellos se puede citar a algunos destacados comerciantes de la Carrera de Indias como Ángel Martín Iribarren, Mauricio Jacobo Lobé, Carlos Filoz, José Retortillo (en 1798 obtiene el título de Conde de Torres), Jaime Picaluga, Benito Picardo, Antonio María Picardo...

21 AHPT, FZC, 1142/60, Cádiz el 7 de noviembre de 1797, de Pedro Domecq a Juan Cólogan-

22 Pedro Domecq señala en sus cartas remitidas a Thomas Cólogan los días 4,18 y 25 de febrero y 1 de marzo, que son la respuesta a las enviadas por Cólogan los días 28, 11, 15 y 18 y 25 respectivamente. En el mes de diciembre ocurre lo mismo, las cartas de remitidas desde Cádiz los días 9 y 16 de diciembre responden a sendas cartas del 2 y 9 de diciembre enviadas desde Canarias. AHPT, FZC, 1004.

23 Diario de la Vigía. Biblioteca Unicaja de Temas gaditanos "Juvencio Maeztu". 


\section{Cuadro 1}

Movimiento de embarcaciones entre Cádiz y Canarias según el Diario de la Vigía (1790-1799)

\begin{tabular}{|c|c|c|c|c|c|c|c|c|c|}
\hline & 1790 & 1791 & $1792^{*}$ & $1793^{*}$ & 1794 & 1795 & $1796^{*}$ & 1798 & 1799 \\
\hline Entradas & 4 & 5 & 5 & & 14 & & 1 & 2 & 7 \\
\hline Salidas & 3 & 12 & 11 & 1 & 19 & & 1 & 2 & 5 \\
\hline
\end{tabular}

*Estos años están incompletos.

\section{Fuente: Diario de La Vigía. Biblioteca Unicaja de Temas gaditanos "Juvencio Maeztu"}

Los datos resumidos en el Cuadro 1 son una mera aproximación no solo por las lagunas de la documentación, sino porque el citado Diario no recoge las embarcaciones menores que entraron en Cádiz, aunque considera que anualmente eran más de cuarenta. Es muy probable que entre estas embarcaciones menores pudiera haber algunas procedentes de Canarias que no se registran individualizadamente. No obstante, el cuadro precedente ofrece una evidencia de la realidad de la navegación con las islas. Se observa cierta superioridad numérica de las salidas sobre las entradas, en algunos años, que pueden reflejar esas derrotas rápidas y directas a la ida, que mencionaba más arriba, y en las que Cádiz podía ser no solo puerto de origen para los barcos que iban directamente a Canarias, sino puerto de transbordo de mercancías procedentes, por ejemplo del Mediterráneo, o podía ser también puerto de escala para las embarcaciones que iban a Estados Unidos o a las Indias Orientales. En esos mismos años, el número de embarcaciones arribadas a Cádiz procedentes de Canarias era notablemente menor, bien por ser más larga la navegación, o bien porque muchas embarcaciones optaran por escalas intermedias, en Algeciras ${ }^{24}$ o en las costas de Portugal y, en tiempos de guerra, en las costas africanas ${ }^{25}$.

Los conflictos bélicos, añadían incertidumbre a las comunicaciones. Durante la guerra con Inglaterra (1797-1801) el correo marítimo de La Coruña estuvo detenido en varias ocasiones

24 AHPT, FZC 1142/60 el bergantín genovés San Vicente Ferrer, capitán Camilo Vasallo, que había salido de Tenerife con judías y almendras para Jacobo Gough, todavía no había llegado y venía desde Algeciras. Este barco terminó siendo apresado en Algeciras por el Juez de Marina pues sospechaba que llevaba carga para Gibraltar. Por los daños causados por la detención indebida, el juez hubo de indemnizar a los consignatarios con el abono de la mitad del flete. AHPT, FZC 1165/63, 65.

25 En carta de 5 de noviembre de 1799 Pedro Domecq asegura a Juan Cólogan que tanto el comercio como la correspondencia se hace "por la polacra marroquí, la Mesouda". AHPT, FZC, 1165/75. 
dando lugar a la acumulación de la correspondencia y a un peculiar peligro: dado que los originales, los duplicados y hasta triplicados de las cartas iban por el mismo correo, podía suceder que la captura del barco correo llevara a los apresadores a extorsionar a los comerciantes $^{26}$, por lo que el gobierno dispuso, a solicitud del comercio, que los originales y duplicados fueran en embarcaciones distintas ${ }^{27}$.

La solución, a los problemas de comunicación ocasionados por la guerra, pasaba por buscar alternativas creativas y, tanto en Cádiz como en Tenerife, Gough y Cólogan recurrieron a los barcos neutrales, no solo para el transporte de mercancías, sino también para el intercambio de la correspondencia. Así, algún barco genovés sirvió de improvisado correo marítimo, aunque Pedro Domecq confesaba cierta desconfianza hacia los genoveses ya que solían "echar al agua toda la correspondencia que llevaban, siempre que se viesen apurado por los enemigos en alguna visita de ellos, pues suelen hacerlas tan rigurosas (las inspecciones) a los neutrales que estos para evitar detenciones echan a la mar cuanto puede dar la menor sospecha". De hecho, a finales de noviembre los genoveses ya no se atrevían a salir debido a la noticia "recibida últimamente de haber sido apresados unos cuantos de ellos" $^{28}$. Pero la vía habitual de comunicación entre Cádiz y las islas a finales de la década de los noventa, eran las embarcaciones marroquíes cuya presencia en el puerto de Cádiz se incrementó de manera desproporcionada entre 1797 y $1799^{29}$; y también los barcos estadounidenses que, solían hacer escala en Tenerife en su viaje con destino en la península y en su regreso a los puertos norteamericanos ${ }^{30}$. Incluso hubo algunas de estas últimas que encontraron "muchas utilidades" en los viajes regulares entre Cádiz y Canarias. ${ }^{31}$.

26 El correo marítimo el Infante fue apresado al salir de La Coruña. Cádiz 27 de octubre de 1797, de Pedro Domecq a Juan Cólogan, AHPT, FZC, 1142/19 y Cádiz 7 de noviembre de 1797, donde Pedro Domecq asegura que ha recibido juntas las cartas del 20 de julio, 5 de agosto y 11 y 18 de septiembre y 2 de octubre. 1142/60. La comunicación epistolar entre los Gough y los Cólogan estuvo interrumpida meses debido a la guerra, y al riesgo de apresamiento.

27 Cádiz 15 de marzo de 1799, de Pedro Domecq a Juan Cólogan e Hijos. AHPT, FZC, 1165/70.

28 AHPT, FZC 1157/44, Cádiz 16 de noviembre de 1798.

29 Véase Cuadro 3. Sin embargo, a finales de 1799 llegan noticias poco alentadoras del apresamiento también de barcos marroquíes, por los que los comerciantes serán a partir de entonces renuentes a fletar estas embarcaciones. De Pedro Domercq a Juan Cólogan e Hijos, Cádiz 18 de octubre de 1799, AHPT, FZC 1186/63.

30 En la carta del 7 de noviembre de 1797 Pedro Domeq le notifica a Juan Cólogan que “he tomado nota de la orden de vms para la remisión por el primer barco neutral que haiga, de un balón u dos de papel de escribir. Por no ir esta goleta Buthy en derechura a essas Yslas poniendo en duda el capitán si pasará a ellas desde la Madera, su destino; no determino arriesgar por ella dicho papel, pero atendiendo a la falta que les hace este renglón en su escritorio, he entregado al capitan de la referida goleta dos resmas rotuladas a vms con particular encargo de cuidar de su envío con las cartas, siempre que no vaya a Canarias", AHPT, FZC, 1142/60.

31 En 1792 el bergantín americano Despacht, viajó desde Filadelfia a Tenerife donde descargó parte delas mercancías, recogió correo y se dirigió a Cádiz, para salir desde allí con correspondencia, sal y sherry hacia Tenerife y Filadelfia. Nueva York 2 de mayo de 1792, de W Green a Juan Cólogan, AHPT, FZC, 1033/24 y Cádiz 30 de septiembre de 1792, de Pedro Domecq a Juan Cólogan, AHPT, FZC, 1031/14. 
Mención aparte merece la interrupción de la correspondencia con Francia en el año 1793 con motivo de la guerra, ya que si bien no afectó a las comunicaciones con Canarias si se vieron perjudicadas las relaciones comerciales y financieras con las casas francesas:

"Los franceses han cortado toda correspondencia con España e Inglaterra $\gamma$ hace dos correos que no parecen cartas de Francia; no sabemos si subsistirá semejante desorden tan perjudicial particularmente al comercio" ${ }^{\prime \prime 2}$.

Sin embargo, parece que en mayo se pudo restablecer la comunicación, ya que volvieron a llegar las cartas de la casa parisina Le Coulteaux con quien Cólogan mantenía negocios derivados de los pagos de letras de cambio.

A pesar de todas estas circunstancias, incluso en un año de guerra como 1797 las cartas llegaron a su destinatario sin demasiados problemas y así lo expone P. Domecq cuando hace el inventario de las cartas recibidas en ese año, pero excusa "hacer lo mismo con las cartas que he escrito a vms porque por sus contestaciones veo que todas han llegado a sus manos, esto es, sus originales u copias" ${ }^{33}$.

\section{LOS NEGOCIOS ENTRE CÁDIZ Y CANARIAS EN LA CORRESPONDENCIA DE LA COMPAÑÍA} GOUGH

La correspondencia epistolar que aquí se analiza desvela, por supuesto, los intereses comerciales de los Cólogan, que ya han sido estudiados por A. Guimerá Ravina ${ }^{34}$, y en los que yo no voy a profundizar; pero, además, al considerar solo las cartas remitidas desde Cádiz, sin prestar atención a la respuesta o al resultado del encargo o negocio, la correspondencia descubre también la realidad comercial y financiera de Cádiz, la volatilidad de su mercado y la vulnerabilidad de dicha plaza a los conflictos. Por eso, el análisis del contenido de esta correspondencia se plantea desde Cádiz y en Cádiz. Esta perspectiva unívoca, puede ayudar a ampliar nuestros conocimientos acerca de los usos comerciales, de la práctica aseguradora, de la dinámica del mercado de algunos de los géneros que se negociaban, así como del tráfico de letras de cambio, o del funcionamiento de los vales reales en el mercado gaditano.

32 AHPT, FZC, 1042/20, Cádiz 11 de mayo de 1793.

33 AHPT, FZC, 1142/60, Cádiz 7 de noviembre de 1797.

34 GUIMERA RAVINA, Agustín. op. cit. 


\section{1. “ES MEJOR ASEGURAR EN CÁDIZ DONDE LOS ASEGURADORES SON MÁS CORRIENTES"}

Una de las ocupaciones principales de la casa Gough era la contratación de los seguros para cualquier tipo de mercancías que los Cólogan compraran o vendieran. Cádiz, al tiempo que plaza comercial, se había convertido en el último cuarto del siglo XVIII en la principal plaza aseguradora española ${ }^{35}$. Los libros diarios de la casa Cólogan para el periodo aquí considerado de 1790-1799, muestran la importancia y la capacidad del mercado asegurador gaditano. Efectivamente, según la contabilidad diaria en esos años, la casa Cólogan anotó la contratación de 122 pólizas de seguro, un 56\% de las cuales fueron formalizadas en Londres por Cólogan, Pollard \& Cooper y el 44\% restante se corrieron en Cádiz por mano de la compañía Gough ${ }^{36}$. Sin embargo, la contratación no se repartió a lo largo de todos los años de la década, sino que se concentró entre 1790 y $1796^{37}$. El temor a un nuevo conflicto tras la firma de la paz de Basilea, primero, y el inicio de las hostilidades con Inglaterra a partir de mediados de 1796, provocó, por un lado, el cierre o la suspensión de actividad de muchas de las compañías de seguros gaditanas ${ }^{38}$ y, por otro, el encarecimiento de los premios de las pólizas en las compañías que se mantuvieron activas, lo cual explicaría la casi total ausencia de apuntes de seguros en los libros diarios de la casa Cólogan desde 1796. Hasta 1802 no volvió a contratarse ningún seguro salvo el que se hizo el 22 de febrero de 1799, para asegurar, en Cádiz un cargamento de trigo y cebada por cuenta del cabildo de Santa Cruz, desde Mogador a Santa Cruz de Tenerife en el barco marroquí La Suara, por valor de 860 pesos $^{39}$.

Se puede deducir de ello que la guerra fue el único agente desestabilizador del mercado asegurador gaditano, no solo porque los aseguradores se retiraban de la contratación ante el incremento de los riesgos, sino porque aquellos que mantuvieron su actividad aseguradora se vieron obligados a introducir factores correctores del precio de las primas

35 Considerando el año 1795, en Cádiz había 75 compañías, en Barcelona 3, en Málaga 2, en La Coruña 2, en Sevilla 3, en Santander 1 y en Alicante 2. TORTELLA CASARES, Gabriel (dir.). Historia del seguro en España, Madrid, Fundación Mapfre, 2014, p. 58. Sobre Cádiz como mercado asegurador véase: CARRASCO GONZÁLEZ, Guadalupe. “El negocio de los seguros marítimos en Cádiz a finales del siglo XVIII", Hispania, LIX/1, 201(1999), PP. 269-304.

36 Véanse los datos recogidos en los anexos por PÉREZ PÉREZ, Jonatan Adonai. Comercio exterior, guerra $\gamma$ seguros marítimos. El ejemplo isleño (1790-1820) Memoria del Trabajo de Fin de Grado, Grado en Economía, Universidad de la Laguna, La Laguna, a 27 de julio de 2015 [en línea]. Comercio exterior, guerra y seguros maritimos. El ejemplo isleno (1790-1820).pdf;jsessionid=E8829D226343259C0A1A4A2218AF7124 (ull.es)

37 Las pólizas formalizadas en Cádiz se abrieron entre 1790 y 1795; en 1796 todas las pólizas abiertas se hicieron en Londres.

38 AHPT, FZC, 1111/54

39 AHPT, FZC 1165/72 
en sus pólizas para cubrir los riesgos derivados, en caso de conflicto ${ }^{40}$. El 31 de julio de 1790 la casa Gough contrataba un seguro de 900 pesos de 128 cuartos sobre un cargamento de azúcar, desde La Habana a Cádiz, con un premio del 1 1/2\%, y un sobrepremio del 20\% en caso de hostilidades o declaración de guerra ${ }^{41}$. Tres años después el 11 de septiembre de 1793 y en plena guerra con Francia, las condiciones de los aseguradores eran mucho más duras, de modo que el seguro que Gough había negociado para las 10 botijas de vino que la casa Cólogan planeaba enviar desde Tenerife a La Habana, en el bergantín Santo Cristo de los Dolores del cargo de José Antonio de Abreu, se harían con un premio de 16\% si el navío navegaba solo, para devolver un $8 \%$ si llegaba felizmente a su destino, o bien al 12\% si navegaba bajo convoy de buque de guerra, devolviendo el 6\% si llegaba a salvamento. Pedro Domecq instaba en sus cartas, por tanto, a Tomas Cólogan para que informara cuanto antes sobre los términos en que se había hecho el viaje para poder cerrar la póliza ${ }^{42}$.

En el Cuadro 2 se han resumido los datos que sobre los premios de los seguros se han encontrado en las cartas remitidas por Eduardo y Jacobo Gough, compañía. En él se puede observar cómo el incremento de riesgos provocado por un conflicto bélico encarecía notablemente las primas. De hecho, la fecha exacta de inicio de un conflicto era muy importante a la hora de fijar los premios en la apertura de una póliza, así "aunque los franceses no declararon la guerra a los españoles hasta el 6 de marzo se sabe que el 26 de febrero (los franceses) habían ya dado patentes para corso contra los españoles", por eso en la póliza que abrieron los Gough en marzo de 1793 el premio cambiaba en función de la fecha de partida de los barcos, siendo del 2\% siempre que hubieran salido antes del 15 de febrero y del 10\% en caso de haberlo hecho después de esa fecha. Por tanto, Pedro Domecq solicitaba nuevamente a la casa Cólogan que informara sobre la fecha concreta de salida desde Tenerife, para poder arreglar el seguro de Tenerife a La Habana sobre aguardiente. El seguro se formalizó finalmente el 13 de mayo de 1793 , al 10\% ${ }^{43}$.

40 Jacobo Gough explica a Juan Cólogan las dificultades para hacer seguros en Cádiz porque "el haberse cerrado estas compañías de seguros en no querer firmar riesgo alguno mientras no se aclaren las cosas, me impide extender seguro", AHPT, FZC, 1111/54, Cádiz 30 de agosto de 1796. "De las dos o tres compañías de seguros buenas que han quedado en esta Plaza en disposicion de firmar, solamente una de ellas hubiera tomado este riesgo, al premio de 60\% reducido a 15\% en llegando a salvamento". AHPT, FZC, 1165/69, Cádiz 31 de Mayo de 1799.

41 AHPT, FZC, 980/50 Cádiz 31 de julio de 1790.

42 AHPT, FZC, 1042/28 Cádiz 11 de septiembre de 1793.

43 AHPT, FZC, 1042/05 Cádiz 15 de marzo de 1793 


\section{Cuadro 2}

Precio de las primas de los seguros en Cádiz según trayecto, halladas en las cartas remitidas por Eduardo y Jacobo Gough, compañía, de Cádiz a la casa Cólogan, de Tenerife (1790-1799)

\begin{tabular}{|c|c|c|}
\hline Trayecto & $\begin{array}{l}\text { Premio del seguro } \\
\text { en tiempo de paz }\end{array}$ & $\begin{array}{l}\text { Premio en } \\
\text { tiempo de } \\
\text { guerra }^{44}\end{array}$ \\
\hline Tenerife-La Guaira & $11 / 4 \% 45$ & $8 \%$ a $12 \% 46$ \\
\hline Orotava-Hamburgo & $13 / 4 \% 47$ & \\
\hline Barcelona-Cádiz-Tenerife & $11 / 2 \% 48$ & \\
\hline Tenerife-La Habana 49 & $11 / 4 \% 50$ & $10 \%$ a $12 \% 51$ \\
\hline La Habana-Tenerife & $11 / 4 \%$ & \\
\hline La Habana-Cádiz & $1 \frac{1 / 2}{5} 52$ & \\
\hline Canarias- Cádiz & $1 \% 53$ & \\
\hline Cádiz - Tenerife & $1 \% 54$ & $5 \%$ a $33 / 4 \% 55$ \\
\hline Cádiz - La Habana & $11 / 4 \% 56$ & \\
\hline
\end{tabular}

44 Las primas dependían de si el barco era neutral o viajaba en convoy.

45 AHPT, FZC, 1009/01 Cádiz 25 de noviembre de 1791

46 AHPT, FZC, 1042/31 Cádiz 16 de abril de 1793

47 AHPT, FZC, 1009/01 Cádiz 25 de noviembre de 1791

48 AHPT, FZC, 1029/31. Cádiz 3 de enero de 1792, AHPT, FZC, 1031/11 Cádiz 11 de febrero de 1792

49 AHPT, FZC, 1029/31. Cádiz 3 de enero de 1792, AHPT, FZC, 1031/11 Cádiz 11 de febrero de 1792

50 AHPT, FZC, 1029/31. Cádiz 3 de enero de 1792, AHPT, FZC, 1031/11 Cádiz 11 de febrero de 1792

51 AHPT, FZC, 1042/31 Cádiz 16 de abril de 1793

52 AHPT, FZC, 1029/31. Cádiz 3 de enero de 1792, AHPT, FZC, 1031/11 Cádiz 11 de febrero de 1792

53 AHPT, FZC, 1029/33, Cádiz 4 de febrero de 1792 y 1031/11, Cádiz 11 de febrero de 1792

54 AHPT, FZC 1029/33 Cádiz 4 de febrero de 1792 y 1031/11 Cádiz 11 de febrero de 1792

55 AHPT, FZC 1042/33 Cádiz 23 de abril de 1793.

56 AHPT, FZC 1029/33 Cádiz 4 de febrero de 1792 y 1031/11 Cádiz 11 de febrero de 1792 


\begin{tabular}{|c|c|c|}
\hline Cádiz-Campeche & $13 / 4 \% 57$ & \\
\hline Cádiz - Filadelfia & $11 / 4 \% 58$ & \\
\hline Filadelfia-Cádiz-Tenerife & $11 / 2 \% 59$ & \\
\hline Tenerife-Charleston & $11 / 4 \% 60$ & \\
\hline $\begin{array}{c}\text { Tenerife - Nueva York - } \\
\text { Boston }\end{array}$ & $11 / 4 \% 61$ & $33 / 4 \% 62$ \\
\hline Tenerife - Plymouth & $11 / 2 \% 63$ & $71 / 2 \%$ a $15 \% 64$ \\
\hline
\end{tabular}

\section{Fuente: Archivo Histórico Provincial de Santa Cruz de Tenerife, Fondo Zárate-Cólogan.}

Los barcos neutrales fueron colaboradores necesarios en el tráfico comercial, simplificando en cierta medida los problemas de conectividad causados por las guerras. Ya hemos señalado la presencia habitual de barcos de nacionalidad estadounidense que como neutrales en los conflictos, navegaron con regularidad entre Cádiz y Canarias. Sin embargo, a pesar de su condición de neutrales, no se vieron libres del acoso de los beligerantes, lo cual repercutió directamente en el precio de los seguros. Así, en la carta de 20 de agosto Jacobo Gough explicaba lo trabajoso que había sido abrir una póliza para embarcar vinos en la goleta americana Rebecca con destino a Nueva York y Boston de cuenta y riesgo de los mercaderes Le Roy y Bayard, "pues ha costado a 3 3/4\% neto aunque no están muy seguros (los aseguradores) de poder mantener este precio por el rumor que corre de que los ingleses no están muy acordes con los americanos" $^{\prime 65}$. A ello hubo que sumar el conflicto entre Estados Unidos y los argelinos que persuadió a las compañías aseguradoras de Cádiz para no abrir pólizas sobre barcos estadounidenses en octubre de 1793; situación que se vio agravada por la tregua que Portugal firmó

\footnotetext{
57 AHPT, FZC 1029/33 Cádiz 4 de febrero de 1792 y 1031/11 Cádiz 11 de febrero de 1792

58 AHPT, FZC 1033 Cádiz 23 de julio de 1792

59 AHPT, FZC 1033 Cádiz 23 de julio de 1792

60 AHPT, FZC 1031/18 Cádiz 10 de agosto de 1792

61 AHPT, FZC 1031/18 Cádiz 10 de agosto de 1792

62 AHPT, FZC 1042/17 Cádiz 20 de agosto de 1793

63 AHPT, FZC 1111/57 Cádiz 22 de marzo de 1796

64 AHPT, FZC 1111/57 Cádiz 22 de marzo de 1796

65 AHPT, FZC 1042/17
} 
con las Regencias, que implicaba de facto la retirada del escuadrón portugués del estrecho de Gibraltar, que había impedido hasta entonces la salida de los corsarios argelinos al Atlánti$\mathrm{CO}^{66}$. Jacobo Gouhg comentaba la noticia indicando que hasta catorce barcos estadounidenses con harinas y trigo habían sido capturados por los argelinos "a este lado del estrecho" 67 .

Las pólizas que se contrataban en Cádiz tenían una duración máxima de dos años, de manera que en ese lapso de tiempo las condiciones pactadas inicialmente podían ser modificadas por el asegurado y por el asegurador. Así, el 4 de febrero de 1792 Pedro Domecq notificaba a Tomás Cólogan que había asegurado un cargamento de 500 libras de seda en rama desde Canarias a Cádiz, por 1000 pesos fuertes, al 1\%68, pero el 17 de febrero se vieron obligados a ampliar la póliza a 1600 pesos fuertes, porque se habían añadido 13 sacas más de seda en rama ${ }^{69}$. Por tanto, una vez abierta la póliza, cualquier cambio en las condiciones estaba sujeto a negociación entre las partes:

"Ya dijimos a vms que el seguro hecho de 6000 pesos sobre los retornos que puede hacer don Tomas de Juare de La Habana por cuenta de vms es sobre frutos $\gamma$ efectivo, a verificarse en esta o en esa; $\gamma$ bajo esta concepto resulta asegurada la cantidad de los 1540 pesos que vms citan $\gamma$ esperaban por un bergantin cupo nombre ignoraban $\gamma$ a su tiempo nos darán razón de este o cualquier retorno que pueda verificarse aplicable a dicha poliza para podernos entender con los aseguradores"

Naturalmente, la apertura de una póliza de seguros, conllevaba una serie de gastos, además de la prima, premio o precio del seguro. Regularmente, a ésta se sumaban una comisión del $1 / 2 \%$ y el corretaje de $1 / 4 \%$, a lo que había que añadir el precio del impreso de la póliza que solía ser de 18 reales de plata $^{71}$. Con todo ello la contratación de un seguro sobre harina o vinos, por ejemplo, venía a representar un gasto de entre el 1,5\% o 1,6\% del capital asegurado en un contexto de estabilidad internacional y del 3\% al 3,5\% cuando las situación geopolítica se enrarecía.

\footnotetext{
66 AHPT, FZC 1042/01 Cádiz 26 de octubre de 1793

67 AHPT, FZC, 1042/43 Cádiz 17 de diciembre de 1793

68 AHPT, FZC, 1029/33

69 AHPT, FZC, 1029/34

70 AHPT, FZC, 1031/14

71 AHPT, FZC, 1111/42, Cádiz 21 de junio de 1796
} 


\subsection{EN CÁDIZ “ESTAMOS NADANDO EN HARINAS...”}

Al tiempo que mercado asegurador, Cádiz se convirtió a finales del siglo XVIII y principios del XIX en el principal puerto de entrada de los granos y de las harinas extranjeras ${ }^{72}$. La especulación con el trigo y la harina que llegada a su puerto en embarcaciones procedentes de Marruecos y sobretodo de Estados Unidos, constituye unos de los temas principales de la correspondencia remitida por la casa Gough.

Estas importaciones fueron muy importantes en todas las poblaciones costeras españo$\operatorname{las}^{73}$, que tradicionalmente se abastecían no solo de la producción propia sino de los granos traídos de Sicilia, Inglaterra y el Báltico. Según J.I. Martínez Ruiz ${ }^{74}$, en Cádiz, las autoridades se vieron obligadas a admitir regularmente esas importaciones para evitar el aumento de los precios, optando por una estrategia que combinaba la regulación del mercado por parte del municipio a través de la alhóndiga, con la actuación de los comerciantes de granos, en un contexto de exención de derechos para el trigo ultramarino. En los últimos años del siglo XVIII la situación del aprovisionamiento de trigos y harinas en Cádiz se agravó debido a la concatenación de varios años de malas cosechas en la Baja Andalucía y a la escasez provocada por las guerras con Gran Bretaña (1779-1783, 17961802) y Francia (1793-1795) que obligaron a la entrada incesante de trigo procedente del norte de África y Norteamérica y de harinas de Estados Unidos.

En este contexto de crisis agrarias recurrentes y guerras encadenadas surgiría una marcada demanda de los grandes productos agrícolas básicos. Los riesgos de transportar estos artículos a través de los mares, frente a los obstáculos interpuestos al comercio marítimo aumentaron el carácter especulativo de este tráfico.

Pero no se puede entender el comercio del trigo y las harinas con España y en particular con Cádiz, sin insertarlo en el contexto de los circuitos coloniales. Las misivas que la casa Gough remitió a los comerciantes de Tenerife informaban acerca del lucrativo negocio

\footnotetext{
72 MARTINEZ RUIZ, José Ignacio. "El mercado internacional de cereales y harinas y el abastecimiento de la periferia española en la segunda mitad del siglo XVIII: Cádiz, entre la regulación y el mercado", Investigaciones de Historia Económica, 1(2005), p. 48,

73 Para Alicante véase GIMÉNEZ LÓPEZ, Enrique. Alicante en el siglo XVIII: economía de una ciudad portuaria en el Antiguo Régimen, Valencia, Institución Alfonso el Magnánimo, 1981; para Valencia, PALOP, José Miguel. Hambre y lucha antifeudal. Las crisis de subsistencias en Valencia (Siglo XVIII), Madrid, Siglo XXI, 1977 y para Barcelona, VILAR, Pierre. Catalunya dins l'Espanya Moderna, Barcelona, Edicions 62, (1962-64), tomo III.

74 MARTINEZ RUIZ, José Ignacio. op. cit., p.49.
} 
en el que se había convertido la importación de estos productos. En sus cartas, Pedro Domecq advertía puntualmente del estado del mercado de la harina en Cádiz, de la llegada incesante de embarcaciones y de sus precios en Cádiz y también en Caracas y La Habana. Como agente de la casa Cólogan, a quien venían consignados muchos de esos barcos cargados con harinas, aconsejaba sobre la reexportación y/o sobre el almacenamiento del trigo o de la harina, para conseguir los mejores precios.

La exportación de granos y harinas a Europa y a las Indias se convirtió después de la Independencia de Estados Unidos en uno de los principales negocios para los mercaderes estadounidenses. La compañía Willing, Morris \& Swanwick, John Voughan, la casa Craig y la casa Sarmiento, de Filadelfia eran nombres habituales en la remisión de provisiones a los puertos españoles ${ }^{75}$. En este negocio confluyeron tanto los intereses de los comerciantes españoles, de la península y de las islas Canarias, como de los mercaderes estadounidenses. Según M. Hernández González ${ }^{76}$ la real orden publicada en 1785 que permitía el abastecimiento de harinas de cualquier origen a Cuba, originó un brusco incremento de las exportaciones de harinas norteamericanas desde Canarias. Allí, los barcos se fletaban con cargamentos de vinos con destino a Estados Unidos. A su arribo, se cargaban con harina hasta Tenerife, desde donde, el mismo navío con la carga de harina, se fletaba para La Habana. Otra opción, era la obtención de licencias que permitieran embarcar vino en navíos canarios hacia Estados Unidos y a su vuelta tocar en La Habana y dejar harina. El retorno, se podía hacer en lastre o en dinero o azúcar. Sin embargo, esta práctica chocaría con los intereses del comercio gaditano que presionó a la corona, obteniendo la real orden de 22 de noviembre de 1791 que gravaba este comercio, terminando así con la reexportación de las harinas norteamericanas a Cuba desde Canarias. A partir de entonces todo el flujo reexportador se llevaría a cabo desde los puertos peninsulares y particularmente desde Cádiz, tal y como harán los Cólogan a través de sus correspondientes en Cádiz.

\footnotetext{
75 LYDON, James G. "Fish and Flour for Gold: Southern Europe and the Colonial American Balance of Payments", Business History Review, XXXIX, 1965, Pp. 171-183. GALPIN, William F. The American Grain Trade to the Spanish Peninsula, 1810-1814, The American Historical Review, vol. 28, issue 1, 1922, PP. 24-44. GONZÁLEZ ENCISO, Agustín. España $\gamma$ USA en el siglo XVIII (Crecimiento industrial comparado y relaciones comerciales), Valladolid, Universidad, 1979 y del mismo autor Exportaciones norteamericanas a Cádiz (1805-1813), Moneda y Crédito, 151, 1979, PP. 51-78. CARRASCO GONZÁLEZ, Guadalupe. Vino, sal y pasas por harina pescado y duelas: El tráfico marítimo comercial estadounidense con España a finales del siglo XVIII (1780-1800). Una primera aproximación, Studia Historica, 42 (1), 2020, doi:10.14201/ shhmo2020421165193

76 HERNÁNDEZ GONZÁLEZ, Manuel. La época dorada de la reexportación de harinas norteamericanas a Cuba en Estados Unidos y Canarias. Comercio e Ilustración .Una mirada Atlántica, Santa Cruz de Tenerife, Ediciones Idea, 2016, pp. 37-50.
} 
Los mercaderes norteamericanos participaron abiertamente en este tráfico a través de Cádiz, colaborando con embarcaciones que se especializaron en estos viajes. Así, William Green de Nueva York escribía a Juan Cólogan en 1792, con el ánimo de que colaborara en el proyecto de construcción de una embarcación de hasta doscientas toneladas que se mantendría en un comercio continuo entre Tenerife o Cádiz con La Habana, bien con la bandera española o la estadounidense, but constantly to take this ports in rotation ${ }^{77}$.

La correspondencia remitida por Pedro Domecq a la casa Cólogan abunda en estos ejemplos. Algunos de estos barcos eran el Dispacht, el Industry, el Mary, el Raquel, el Rebecca, el Rambler, el Eliza, el Sally que serán fletados en puertos estadounidenses por cuenta de comerciantes como la compañía Willing, Morris \& Swanwick, Juan Vaughan, John Barclay, John Craig de Filadelfia o la casa de negocios Le Roy y Bayard de Nueva York y por cuenta de los Cólogan y otros comerciantes de Cádiz como Mauricio Roberts, Domingo Terry o Benito de la Piedra ${ }^{78}$ con importantes cargamentos de harina, trigo, arroz.

El cuadro 3 muestra el flujo creciente barcos estadounidenses a Cádiz en la década de los noventa, que también se refleja en la correspondencia remitida por Gough, hasta el punto de que el 23 de julio de 1792, Pedro Domecq habla en su carta de que "estamos inundados en harinas en Cádiz, que no paran de llegar" y en agosto añade que "llegan infinitos barcos de aquel continente" (América del norte) ${ }^{79}$. Esta abundancia de harinas provocó la caída de los precios hasta los 9 y 9,5 pesos por barril llegando incluso a los 7,5 pesos por barril a bordo, en el verano de 1792; "con lo que no se cubren ni los gastos" ${ }^{80}$.

Un año antes, en mayo de 1791, los agentes de la casa Gough en las Indias informaban que los precios de la harina se habían mantenido altos en Caracas y La Habana, llegando a los 16 y 15 pesos por barril respectivamente. Pero, a partir de julio de 1792 la abundancia de harinas en La Habana hizo que su cotización también bajara hasta los 13 pesos por barril. Un precio notablemente más alto que el que se ofrecía en Cádiz. Ante esta situación, Pedro Domecq trasladaba a Cólogan la propuesta de Tomas de Juara, agente en la Habana de la casa Cólogan, para que le enviasen hasta 2000 barriles de harina, a cambio de frutos o dinero, con la

77 AHPT, FZC, 1033/24, Nueva York 2 de mayo de 1792.

78 CARRASCO-GONZÁLEZ, Guadalupe. Del patronazgo familiar al conflicto. Creación y disolución de la red comercialfamiliar del comerciante gaditano Diego de la Piedra Secadura, 1750-1845, Investigaciones históricas: Época moderna y contemporánea, 38, 2018, pp. 287-314.

79 AHPT, FZC, 1033/58

80 Ibídem. 
esperanza de que cuando llegase, ya en otoño, "tendrá más estimación por la concurrencia entonces de pocos barcos y ser entrada del invierno" ${ }^{\prime 81}$. Finalmente, ante la incesante llegada de embarcaciones con harina al puerto de Cádiz, algunas con harinas por cuenta de los Cólogan, Pedro Domecq opta por recomendar el envío de la harina a La Habana.

Un año después, sin embargo, la estrategia comercial de la compañía Gough cambió radicalmente. En agosto de 1793 llegó a Cádiz el bergantín americano Despacht, al mando del capitán Benjamin Flod, consignado a la casa Gough y procedente de Filadelfia con un cargamento de 1700 barriles y 60 medios barriles de harina de cuenta de los Cólogan, además de 300 barriles y 20 medios barriles de cuenta de don Pedro Franchis. La casa Gough, por mano de Pedro Domecq, como consignataria, intentó vender a bordo la harina "pero ha sido inútil por cuanto no ofrecen precio proporcionado a su costo, no siendo extraño presentemente en vista de las crecidísimas partidas que han venido". Aprovechando los bajos precios, la alhóndiga gaditana fue capaz de adquirir una importante porción de harinas a 7,5 pesos por barril. Sin embargo, la compañía Gough, no vendió y prefirió descargar su harina y pagar los gastos de su descarga y almacenaje en los almacenes de Puntales a razón de 180 maravedís el quintal, "con la condición de disponer de ella dentro de cuatro meses y en su defecto obligado al pago de derechos de millones" ${ }^{\prime 2}$. La idea era esperar la llegada del invierno ya que entonces la escasez de trigo obligaría a echar mano de la harina, lo que provocaría la consabida subida de su precio. Los comerciantes, según P. Domecq, no querían vender por debajo de 10 u 11 pesos. Por tanto, la solución para la compañía Gough era esperar. En este caso, el arbitrio de recurrir al envío a La Habana no era posible ya que allí la harina había bajado a 7 pesos el barril a cualquier plazo, y aunque habían llegado noticias a Cádiz de que en Caracas las harinas valían a 18 pesos, ya se habían enviado algunas cantidades desde Cádiz y Santander, y en cualquier caso en ese momento no había ningún barco disponible en Cádiz para Caracas.

Finalmente, P. Domecq entró en negociaciones con un comprador por 10,5 pesos al contado. El acuerdo definitivo al que se llegó, con la mediación de un corredor, fue de 10 pesos por barril al contado, que consideraba era justo porque quedaban cubiertos el coste y los gastos "y desde luego vale mas tomar el dinero prompto que contemporizar con su genero expuesto a sufrir en detrimento o correr la suerte de La Habana según vms pensaron al principio, pues según las ultimas noticias se daba allá hasta a 6 pesos por barril" ${ }^{83}$.

\footnotetext{
81 Ibídem

82 AHPT, FZC, 1031/15 Cádiz 31 de agosto de 1793.

83 AHPT, FZC, 1034/12, Cádiz 19 de octubre de 1792.
} 
La preocupación por la excesiva saturación del mercado de la harina en Cádiz, llevó a Pedro Domecq a buscar un experto que pudiera arrojar luz sobre la evolución del mercado. Sin embargo, su opinión se limitó a constatar la realidad:

"Un sujeto que entiende mucho en el ramo de harinas $\gamma$ de quien he tomado informe, nos ha dicho que no es probable de que en adelante baje del precio de 10 pesos el barril despachado, porque además de que puede tener aquí un consumo regular por cuanto no abunda el trigo; en adelante las remesas de la America septentrional no seran tan copiosas como han sido en este año $\gamma$ que naturalmente cargaran la mano para los puertos de Francia donde tienen mayor necesidad $\gamma$ por tanto las que vengan aquí aun en caso de ser muchas, siempre tendrán salida a precio regular porque no faltarán compradores que les convenga darle destino para fuera cuando no tengamos major urgencia..." 84 .

Así pues, la volatilidad de los precios de la harina hacía que fuera difícil predecir su evolución debido a la persistencia de las llegadas de embarcaciones con harinas y a la incertidumbre de su salida hacia el mercado interior peninsular o el colonial. Junto a estos factores, la estacionalidad y los rumores sobre la cosecha siguiente, influían también en su cotización. En un mercado de estas características el experto al que recurrió P. Domecq no se equivocaba en su dictamen, ya que los precios se mantuvieron por encima de los 10 pesos llegando a los 12 pesos el barril cuando la guerra hizo su aparición a partir de marzo de 1793.

Con la guerra se esperaba el despegue de los precios, por eso cuando en la carta fechada el 15 de febrero de 1793, P. Domecq informaba de que los 529 barriles arribados en el Orotava se habían vendido a bordo a 10,5 pesos el barril, a pesar de haber estado algo pasada, los Cólogan mostraron su desacuerdo por este precio que consideraban insuficiente, cuando podían haberla almacenado y vendido más adelante al menos a 11,5 pesos por barril ${ }^{85}$.

84 AHPT, FZC, 1031/04 Cádiz octubre de 1792 de Jacobo Gough a Thomas Cólogan.

85 AHPT, FZC, 102/05 Cádiz 15 de marzo de 1793, de Pedro Domecq a Juan Cólogan e hijos. “Vemos que no están vms muy contentos de la venta de sus 529 barriles de harina, los inteligentes no la juzgaron muy buena y no obstante en aquella epoca vendió mejor que nosotros, es cierto que si lo hubiéramos dilatado por algún tiempo se habría proporcionado mejor precio pero para esto era menester causar gastos no diferentes y assi nos parecio acertado venderla a bordo", Cádiz 16 de abril de 1793, de Pedro Domecq a Juan Cólogan e hijos AHPT, FZC, 1042/31. 


\section{Cuadro 3}

Número de embarcaciones de bandera estadounidense que arribaron a Cádiz entre 1789 y 1799

\begin{tabular}{|c|c|c|}
\hline Años & $\begin{array}{c}\text { Número } \\
\text { de barcos } \\
\text { estadounidenses }\end{array}$ & $\begin{array}{c}\text { Número } \\
\text { de barcos } \\
\text { marroquíes }\end{array}$ \\
\hline 1788 & 38 & \\
\hline 1789 & 55 & \\
\hline 1790 & 55 & \\
\hline 1791 & 142 & 3 \\
\hline 1792 & 162 & \\
\hline 1793 & 43 & \\
\hline 1794 & 82 & \\
\hline 1795 & 54 & 288 \\
\hline 1796 & & 107 \\
\hline 1797 & & \\
\hline 1798 & & \\
\hline 1799 & & \\
\hline 179 & & \\
\hline
\end{tabular}

Fuente: Diario de la Vigía. Biblioteca Unicaja de Temas gaditanos "Juvencio Maeztu"

Entre octubre de 1793 y finales de 1799 las harinas subieron hasta los 13 pesos por barril, aunque a finales de 1793, coyunturalmente se obtuvieron 14, 15 y hasta 16 pesos por barril, debido a la declaración de guerra de Argel contra Estados Unidos. Efectivamente, cuando en Cádiz se conoció la declaración de guerra y que la tregua firmada por Argel y Portugal habían permitido la salida al Atlántico de los corsarios argelinos, las compañías aseguradoras se negaron a tomar riesgos sobre barcos estadounidenses, pero como 
"no hay mal que por bien no venga" ${ }^{86}$, los apresamientos de más de 14 barcos estadounidenses cargados con harinas que se dirigían a la península, contribuyeron a la subida de los precios en el puerto de Cádiz y por tanto a facilitar la venta de la harina que llegó en el navío americano Industry, capitán Guillermo Perry, que procedente de Filadelfia traía 2177 barriles por cuenta de la casa Cólogan y de Juan Vaughan y Willing, Morris \& Swanwick de Filadelfia. El barco se había visto acosado por corsarios argelinos que le obligaron a refugiarse en Faro, llegando felizmente a Cádiz con su carga intacta.

En la correspondencia, el trigo resultó ser un producto de menor interés para los Cólogan. El proveedor principal era Marruecos, y concretamente Mogador, donde los Cólogan tenían correspondencia con la casa de Guillermo Court. De allí se surtía Tenerife directamente en épocas de escasez pero también desde allí se conducía el trigo a Cádiz para su abastecimiento, en los barcos fletados por la casa comercial de Picardo "una de las de primer orden en esta plaza y de más solidez, que ninguna otra le hace ventaja con la circunstancia que tiene en Mogador un tráfico regular porque es una de las que proveen de trigo a este pueblo" ${ }^{87}$. Efectivamente, Benito Picardo era uno de los comerciantes de trigo más importantes de Cádiz a donde lo importada desde Mogador y Sicilia ${ }^{88}$. Entre 1797 y 1799, coincidiendo con el incremento de embarcaciones marroquíes en el puerto de Cádiz (Cuadro 3), aparecen varias cartas remitidas por Antonio María Picardo y Benito Picardo que hacen referencia a diversas partidas de trigo, por cuenta de Juan Cólogan e Hijos, cargadas en barcos marroquís para el abastecimiento de Tenerife y Cádiz ${ }^{89}$.

En los años finales del siglo XVIII, el comercio de granos con Marruecos se intensificaría (Cuadro 3) coincidiendo con la disminución de las llegadas de embarcaciones estadounidenses debido a las epidemias de fiebre amarilla que se padecieron en algunos de sus puertos entre 1793 y 1796, sobre todo en Filadelfia, y a la guerra no declara contra Francia en 1798.

86 AHPT, FZC, 1042/43 Cádiz 17 de diciembre de 1793

87 AHPT, FZC, 1181/45 Cádiz 17 de febrero de 1799, Mateo Ferrero a Juan Cólogan

88 Véase el Diario de la Vigía.

89 AHPT, FZC, 1175/81, Cádiz 3 de abril de 1799, 1186/12, Cádiz 6 de junio de 1799, 1175/81, Cádiz 9 de abril de 1799, de Antonio Picardo a Juan Cólogan y 1171/22, Cádiz 6 de julio de 1799, de Benito Picardo a Juan Cólogan. 


\section{3. “ES NORMAL QUE EN LONDRES Y OTRAS PLAZAS SE QUIERA ESPECULAR CON AÑIL Y AZÚCAR"}

Junto a la harina y los granos las importaciones de productos coloniales como el añil, cacao y, sobre todo, el azúcar fueron una parte importante de los negocios de la casa Cólogan. En las cartas ocupan un lugar relevante las noticias sobre la llegada de remesas de estos frutos en los barcos procedentes de La Guaira, Caracas o La Habana. Pedro Domecq informaba sobre las cantidades y calidades remitidas, los precios de compra y los de venta, la apertura de las pólizas de seguro correspondientes y reflexionaba, también, sobre la evolución del mercado teniendo en cuenta factores como la rebelión de Santo Domingo y la guerra con Inglaterra, para aconsejar sobre estrategias de negocio que pudieran ser ventajosas para la casa Cólogan.

A lo largo de la década de los noventa se produjo una subida constante de los precios del azúcar, pero también del cacao y añil, debido a la destrucción de las haciendas e ingenios provocados por los sucesos en Santo Domingo a partir de agosto de 1791. En la carta de 26 de agosto de 1791 Pedro Domecq animaba a los Cólogan a negociar con azúcar, bien con ventas a bordo o almacenándola; ya que se podían obtener 18 reales de plata por arroba en la azúcar blanca y 15 por la terciada "precios que pueden dejar aquí bastante utilidad y más cuando hay apariencia de que no puede bajar este fruto, antes al contrario" ${ }^{90}$. P. Domecq no se equivocaba y tres meses después escribía a Tomas Cólogan anunciando los sucesos en Santo Domingo y cómo el azúcar había subido hasta los 40 reales de plata la arroba (lo mismo había sucedido con el añil). Un mes después, seguía subiendo hasta los 45 reales de plata por arroba el azúcar blanco.

Los acertados consejos de Domecq habían sido seguidos por los Cólogan que hicieron acopio de azúcar; lo mismo que hicieron otros comerciantes de Cádiz, que viendo "el vuelo que tomaba el azúcar" ${ }^{91}$ retuvieron toda la que llegaba a Cádiz. Ante esta situación de precios altos, Pedro Domecq escribió a Tomas Juara de La Habana aconsejándole emplear todo el dinero de la harina que le enviaban en comprar azúcar, y enviarla a Cádiz, ya que el azúcar de La Habana llegó a alcanzar los 62 y 64 reales de plata la arroba de la blanca y a 54 reales de plata la arroba de la quebrada ${ }^{92}$. La guerra con Francia, pero sobre todo la guerra con Inglaterra elevó aún más la cotización del azúcar y el cacao en los mercados. Las ventas del cacao se mantuvieron

\footnotetext{
90 Cádiz 26 de agosto de 1791.

91 Cádiz 9 y 16 de diciembre de 1791

92 Cádiz 29 de febrero de 1792
} 
en niveles mínimos, limitadas al consumo preciso "siendo este muy corto por razón de los altos precios del azúcar que está de 110 a 116 reales de plata la arroba para el blanco y de 104 a 110 el terciado" ${ }^{\prime \prime}$.

\section{4. “LA CARNE SALADA ES UN GÉNERO QUE TIENE MUCHAS ALTAS Y BAJAS" 94}

La carne salada que se consumía en el mercado español procedía generalmente de Irlanda, aunque también fue un producto habitual en las importaciones de Estados Unidos. En las cartas remitidas por Pedro Domecq encontramos ejemplos de negociación de carne salada de ambas procedencias. Los 12 barriles llegados en el sloop Sally en febrero de 1790 procedente de Nueva York, fueron vendidos sin dificultades en el mercado gaditano en los dos meses siguientes ${ }^{95}$. Sin embargo, la remesa que llegó en mayo de 1792, procedente de Canarias en el barco San Telmo, supuso un reto para la casa Gough. Se trataba de un cargamento de 300 barriles de carne salada de Irlanda que recibieron y tuvieron que almacenar, ya que fue imposible realizar la venta a bordo, al no haber escasez de este género y por tanto ninguna demanda. La única manera de deshacerse de la carne salada era proporcionándola como rancho a los barcos que lo solicitasen, pero teniendo en cuenta que no se podría contar con los barcos del rey porque su abastecimiento se hacía mediante asiento, no quedaba más remedio que armarse de paciencia para poder conseguir la mejor venta posible, Pedro Domecq advertía:

"Que deben saber ustedes que este genero esta sujeto a los siguiente derechos $\gamma$ gastos que debe pagar el comprador o vendedor, que se cargaran en el precio de venta: derechos municipales, sobre 4 reales por barril mas o menos; millones a 4 cuartos de libra regulado cada barril sobre 80 a 83 libras netas; porte a tierra 1 real de plata; marchamo y alcaidía 2,5 reales; porte al almacen a 4 reales" ${ }^{\prime \prime}$.

La carne se almacenó en Puntales con un gravamen extra de 10 pesos mensuales del alquiler de los almacenes. La elección de estos almacenes la explica P. Domecq por "estar más a mano para facilitar su venta para los navíos que necesitan de ella"97.

\footnotetext{
93 Cádiz 6 de noviembre de 1798

94 Cádiz 26 de abril de 1792

95 AHPT, FZC, 981/61, Nueva York 17 de febrero de 1790, de Le Roy Bayard a Juan Cólogan. AHPT, FZC, 980/55 Carta de 27 de abril de 1790 dando cuenta de la venta.

96 AHPT, FZC, 1033/61, Cádiz 14 de mayo de 1792.

97 AHPT, FZC, 1031/13, Cádiz 4 de junio de 1792.
} 
La carne tardó en venderse más de un año, ya que debía competir con la carne de mejor calidad y más barata que llegaba de Estados Unidos y que era adquirida por los Cinco Gremios que tenían asignado el aprovisionamiento de la Armada Real ${ }^{98}$. P. Domecq advertía que "es difícil salir de este empeño sin quebranto" y entre tanto, para mantenerla en buenas condiciones era necesario refrescarla con salmuera en los meses de calor. Finalmente, en febrero de 1793 se vendieron los últimos barriles gracias al trato que había cerrado P. Domecq con los barcos del convoy que se estaba preparando para América99.

Hasta aquí se han descrito algunos negocios que la casa Gough llevó a cabo con los productos más señalados y que son mencionados en las cartas remitidas a los Cólogan de Tenerife. Fueron bastantes más los géneros que se intercambiaron entre Cádiz y Canarias en los que participó la compañía Gough. Merece la pena señalar: la compra de aceite en Sevilla y El Puerto de Santa María, los envíos de seda en rama desde Canarias, las duelas que llegaban a Cádiz en los barcos estadounidenses y que eran reexportadas a Canarias, el vino tinto que regularmente los Cólogan compraban en Barcelona, Salou y Benicarló y que era enviado a Tenerife vía Cádiz, el envío de judías y almendras desde Canarias a Cádiz, la compra y venta de barcos y mercancías apresadas por barcos corsarios llegados a Tenerife y Cádiz, el tráfico de letras de cambio, o el funcionamiento de los vales reales en el mercado de Cádiz.

En general, la correspondencia revela detalles del estado del comercio y de su práctica cotidiana en Cádiz, de la percepción que los comerciantes tenían de los negocios, aunque siempre a corto plazo. Reflejan las incertidumbres provocadas por los acontecimientos que afectaban a los negocios y la impotencia que les provocaba la falta de control sobre ellos. Desde que en 1796 comenzara el conflicto con Inglaterra los hombres del comercio abrigaban la esperanza, en cada carta, de la llegada de la paz y con ella de la reanudación de los negocios aplazados ${ }^{100}$ :

"Luego que se declaró la guerra tomaron mucho vuelo los precios de los frutos de Indias pero sin verificarse ventas de mucha consideración. En el día están todas paradas ynadieseatrevea comprar porespeculación porquemuchos están confiados en una prompta paz"101.

98 AHPT, FZC, 1031/18, Cádiz 10 de agosto de 1792

99 AHPT, FZC, 1042/01,Cádiz 26 de octubre de 1793

100 AHPT, FZC, 1181/46, Cádiz 21 de enero de 1799.

101 AHPT, FZC, 1111/51, Cádiz 18 de noviembre de 1796. 
En septiembre de 1796 los comerciantes buscaban indicios seguros de guerra o de paz, para poder tomar decisiones. Así, la compra encargada desde Madrid de 10.000 cajas de azúcar evidenciaba, para los hombres del comercio, que en la Corte "deben estar muy seguros de la guerra porque de no haberla les resultará un gran quebranto" ${ }^{102}$.

Desde finales de 1796 los Gough tenían pendiente el envío de una partida de sombreros de Córdoba a Canarias, pero los riesgos derivados de la guerra en el mar y en los mercados, y la imposibilidad de hacer un seguro, llegaron a dilatar en el tiempo el envío, hasta que en mayo de 1799 se llegó a plantear la posibilidad de despacharlos sin seguro, fraccionando el envío, para así disminuir los riesgos ${ }^{103}$.

Las cartas remitidas por la casa Gough en la década de los noventa del siglo XVIII reflejan la confusión general en la que se hallaba el comercio, por las quiebras frecuentes, la guerra con Francia y la consiguiente expulsión de los franceses "que se han deshecho de todos sus géneros en sus almacenes haciendo ventas verdaderas o simuladas" ${ }^{104}$ y la guerra con Inglaterra que hacía que se disparasen los precios de los frutos de Indias. Ni siquiera el anuncio de la paz con Francia animaba al comercio ya que "los compradores están remisos a hacer compras de productos de América hasta no saber si resultan o no desavenencias entre las potencias" ${ }^{105}$. En definitiva, a finales del 1798 "el comercio de Cádiz está en decadencia, perdido, no hay casi bandera neutral en Europa, pues los genoveses no se atreven a salir, pues han apresado varios. Los ingleses no han abandonado el bloqueo (de Cádiz) con la estación. Cuando hay apariencia de temporal se alejan un poco y vuelven a aparecer cuando se serena el tiempo" 106 .

102 AHPT, FZC, 1111/53, Cádiz 17 de septiembre de 1796.

103 AHPT, FZC, 1165/69, Cádiz 31 de mayo de 1799.

104 AHPT, FZC, 1042/05, Cádiz 15 de marzo de 1793.

105 AHPT, FZC, 1086/64, Cádiz 27 de agosto de 1795.

106 AHPT, FZC, 1157/46, Cádiz 6 noviembre 1798. 